\title{
Analysis of financial risk of a hard coal mine participation in DSR mechanisms in Poland - a case study
}

\author{
Piotr Olczak ${ }^{1 *}$, Dominik Kryzia ${ }^{1}$, Dominika Matuszewska ${ }^{2}$, and Artur Halbina ${ }^{2}$ \\ ${ }^{1}$ Mineral and Energy Economy Research Institute, Polish Academy of Sciences, 7A Wybickiego St., \\ 31-261 Cracow, Poland \\ ${ }^{2}$ AGH University of Science and Technology, 30 Mickiewicza Ave., 30-059 Cracow, Poland
}

\begin{abstract}
The paper analyses possibilities of a hard coal mine operation as an electricity consumer capable of reducing instantaneous demand for electric power in the case of a Demand Side Response (DSR) call. The analyses considered the risk of service provision or non-provision based on the 2018 data on the electricity consumption and on parameters of the Polish power system. The analyses applied to two types of DSR participation programmes: guaranteed and current, and to an example of hard coal mine from the area of the Upper Silesia, which ordered power was $20 \mathrm{MW}$. For the current programme (without fines for service nonprovision) the optimum value - from the financial risk point of view - was calculated as $6 \mathrm{MW}$, and for the guaranteed programme results were determined depending on the ratio of price for service provision to the fine for non-provision.
\end{abstract}

\section{Introduction}

Because of intensive pursuit of greenhouse gases emission, in particular $\mathrm{CO}_{2}$, the share of controllable generating assets in the energy mix of individual states increasingly changes. This proceeds via replacement of controllable electricity generation sources, such as coalfired power plants with renewable energy sources, which by nature are not controllable. Taking into account such changes a need appears to intensify actions aimed at implementing management of electricity customers, which can be a tool used to maintain the stability of both generation and transmission systems in a given region in the case of significant increase in the demand for electricity and of a shortage of power in the system, which could respond to this increase.

Apart from typical and known for many years solutions in the form of e.g. pumpedstorage power stations and inter-operator assistance (the use of cross-border connections), the implementation of a mechanism related to the demand side response (DSR) is one of possible solutions. This mechanism becomes important as a tool for the power availability management in the power system, especially in critical situations, i.e. during peaks of demand for electricity. The demand side response consist in voluntary and temporary

\footnotetext{
*Corresponding author: piotrolczak@hotmail.com
} 
reduction of electricity consumption by end users or changes of the period, when this energy will be used. The customer response occurs most often to the call of transmission system operator in a given area and is related to the remuneration of the party, which responded and reduced the consumption. The operator - being a party responsible for proper system operation - takes actions aimed at maintaining stability in the regional power system and calls energy customers at defined, difficult balance situations, which can result in a system breakdown, in particular in the periods of peak demand for electricity.

The idea of the demand side response to the transmission system operator's call consists in the reduction of the customer baseline profile by a defined power reduction (M) during the time of reduction block defined in the call. The idea of system operation is presented in Fig. 1, the service provision at 1 o'clock p.m. The plan (without reduction) presents a level of energy consumption typical of a specific customer.

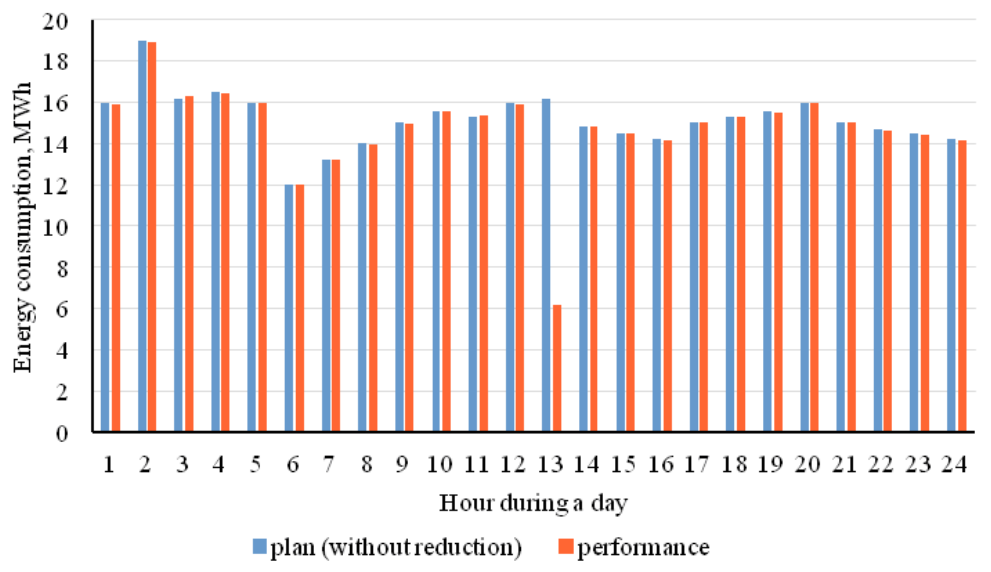

Fig. 1. Example of DSR mechanism action, the service provision at $1 \mathrm{p} . \mathrm{m}$. Source: own study based on [1].

The use of demand side response (DSR) mechanism seems a favourable tool to manage the transmission system stability due to a broad spectrum of possibilities and benefits contributed to the system. The benefits of this tool use may be divided into economic and environmental ones.

Lower marginal costs for all electricity customers are economic benefits related to the use of demand side response mechanisms. This is related to the operation of most efficient generation units and the demand side participation as an active market player. The energy customers offer a price, at which they are ready to give up electricity use, and this price is lower than that of generation units with poor efficiency. Potential benefits for the customers, who participate in actions related to the response to the operator call, are an additional economic benefit.

The environmental effect is the second category of benefits related to the demand side response mechanism use. It consists in the reduction of greenhouse gases and other substances emission to the environment via elimination from the operation of units featuring the worst energy generation parameters.

Albeit the idea of DSR mechanism action described above is universal, the mechanism itself is defined in various ways by transmission system operators in different regions of our world. The DSR is defined by the International Energy Agency (IEA) as the demand side capability to respond to electricity price changes on the energy market or in real time [2]. For the European Network of Transmission System Operators for Electricity (ENTSO-E) the Demand Side Response is defined as voluntary temporary adaptation of the power 
demand, carried out by the end user as a response to a price signal (market price or electricity tariff) or carried out based on a contract with the end user [3]. On the national level the DSR service is a voluntary and temporary reduction of electricity consumption by the users or a shift in time of its consumption to the order of Polish Power Grid (PSE S.A.) (i.e. the transmission system operator in Poland) in exchange for the expected remuneration. Because of that the DSR can contribute to maintaining stability in the Polish power system (KSE) in the case of a difficult balance situation occurrence, in particular at hours of peak electricity demand [4]. For the Energy Users Association of Australia (EUAA), the DSR is defined as electricity users (consumers) or small local energy producers response to a high level of energy prices (or another signal, like the occurrence of limitations in the transmission). In other words, for the EUAA the DSR is an equivalent of the right to choose, which allows the users to make a decision, whether to buy now, refrain from the purchase, buy less/more, or buy in another period $[5,6]$. For the US Department of Energy, the demand side response is a change in the electricity consumption made by the end users with respect to their normal consumption responding to energy price changes or campaigns of paid incentives intended to encourage smaller electricity consumption in periods of high wholesale prices or when the system reliability is threatened [7].

In accordance with the above definitions also a dynamically changing electricity price can be a significant factor of the demand response, which pursuant to definitions of European operators association ENTSO-E, Energy Users Association of Australia, and of the US Department of Energy [1, 3, 8, 9] is a price signal for customers, which determines changes of their baseline profiles.

This paper presents a mechanism related to the demand side response implementation for Polish conditions. The study focuses on the risk assessment of the DSR service introduction in a hard coal mine (KWK). Whereas, further on the economic effects of DSR services provision have been evaluated in such enterprises. An underground hard coal mine situated in the southern-central part of Poland was analysed as a representative enterprise. This mine produces yearly approx. 2 million tonnes of high quality coal.

Both sets of longwall equipment comprise the following machines: longwall powered support sections, a longwall shearer, a stage loader, a crusher, transfer equipment, mine visualisation systems, which monitor the installed machinery. The power ordered by the analysed hard coal mine is $20 \mathrm{MW}$, while the minimum power level, to which the mine can reduce its power during a normal working day is $8 \mathrm{MW}$. Further on a risk analysis and an economic analysis have been presented for the KWK due to the DSR services introduction, which can be a basis for more advanced assessment of DSR service cost in mines and of their profitability level.

\section{Risk analysis}

Since the introduction of DSR service in Poland until now none of entities providing the service was called to reduce the power. Because of that conditions are not known, under which the power reduction would have to occur in an enterprise at the operator call. Therefore, it was necessary to make assumptions in this field. It was considered that the size of thermal power plants power reserve in the Polish power system, available to the Central Dispatcher, is the main factor affecting probability of making a decision on using the DSR service. The power reserve in thermal power plants is defined as a difference between the rated power of electricity generating units from thermal power plants connected to the transmission grid or to coordinated $110 \mathrm{kV}$ grid, subject to central control at a given time by the TSO, and the current load imposed by the TSO. The adopted simplification is dictated by subject-matter premises resulting from the fact that with decreasing size of the thermal power plants power reserve in the system a probability of 
power deficit occurrence increases and hence a probability to reduce power at the enterprise, at the operator's call. Historical values of thermal power reserve at the KSE are available on the website: www.pse.pl. These figures are given for two peaks of energy consumption, which occur during a day at the KSE - the morning and evening peak. The morning peak comprises a period from the morning till afternoon. The evening peak includes afternoon and evening hours. The periods of peaks occurrence differ depending on the season. Table 1 presents the number of electricity demand peak occurrences in consecutive day hours in 2018 , for working days.

Table 1. Frequency of electricity demand peak occurrences in consecutive day hours in 2018, for working days.

\begin{tabular}{|c|c|c|c|c|c|c|c|c|c|c|c|c|c|}
\hline Hour & 8 & 9 & 10 & 11 & 12 & 13 & 16 & 17 & 18 & 19 & 20 & 21 & Total \\
\hline Morning peak & 1 & 10 & 2 & 4 & 6 & 227 & & & & & & & 250 \\
\hline Evening peak & & & & & & & 34 & 40 & 23 & 67 & 55 & 31 & 250 \\
\hline Total & 1 & 10 & 2 & 4 & 6 & 227 & 34 & 40 & 23 & 67 & 55 & 31 & 500 \\
\hline
\end{tabular}

Source: own study based on KSE data.

Fig. 2, presenting cumulative distribution function of reserve size probability for Centrally Controlled Generating Units (JWCD) thermal power plants at the KSE was prepared based on 2018 historical figures. The probability determined in this way does not reflect all aspects related to a specific value of power reserve occurrence, because this issue is not purely random, but depends e.g. on the temperature outside, season of the year, etc., however this analysis utilises the presented simplification.

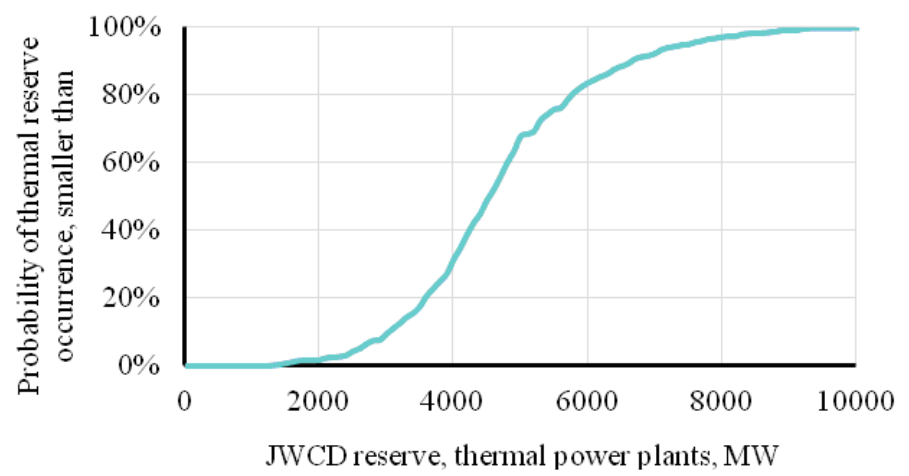

Fig. 2. Probability of thermal JCWD reserve occurrence not higher than that determined based on the 2018 KSE data for morning and evening peaks. Source: own study based on KSE data.

The values of reserve in thermal power plants Centrally Controlled Generating Units (JWCD) in 2018 on working days (when the mine operates) ranged from approx. $1000 \mathrm{MW}$ to approx. $10000 \mathrm{MW}$.

It has been observed that the highest probability of thermal power plants reserve occurrence refers to the range from approx. $3200 \mathrm{MW}$ to $5000 \mathrm{MW}$, a value from this range occurred at least in $50 \%$ cases of peak electricity consumption in Poland. Thermal reserve below $2000 \mathrm{MW}$ occurred at $1.6 \%$ of cases. Fig. 3 presents, how this takes place for individual peak hours.

The morning peak occurred most frequently at 1 p.m., i.e. at more than $80 \%$ of cases. Between 2 and 4 p.m. no consumption peak occurred in 2018 on working days. The evening peak in 2018 occurred between 4 and 9 p.m., in a more even way than the morning peak. 


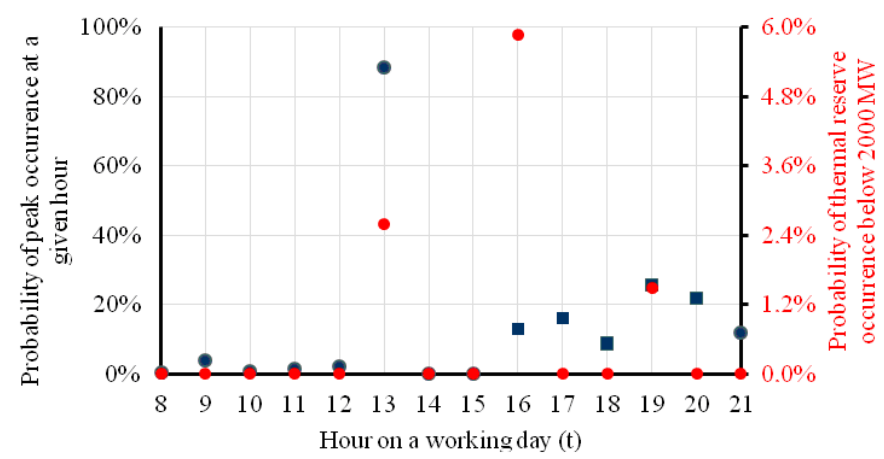

Fig. 3. Probability of the peak demand for energy occurrence at the KSE and of thermal reserve below 2000 MW occurrence for a given hour on working days - morning $(\bullet)$ and evening ( $(\mathbf{)})$ peak. Source: own study based on KSE data.

Based on the data presented in Fig. 3 it is possible to calculate probability of simultaneous occurrence of a peak at a given hour and of thermal reserve below $2000 \mathrm{MW}$ (pw) for working day hours (t). Fig. 4 shows the calculated values (being a product of probabilities of quantities presented in Fig. 3).

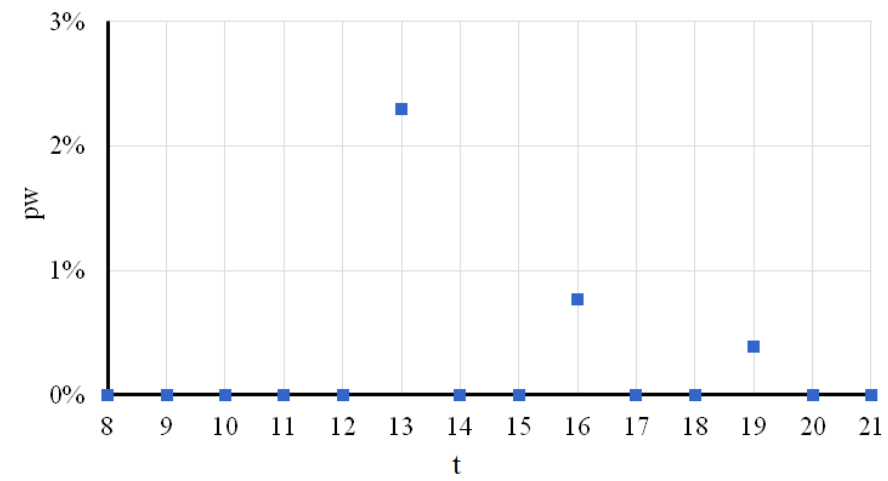

Fig. 4. Probability of thermal reserve occurrence at the KSE system below 2000 MW during the daily demand peak on a specific day versus the hour on a working day. Source: own study.

Results presented in Fig. 4 clearly show three cases, corresponding to 1, 4, and 7 p.m., which were considered in further analyses. The number of potential occurrences of thermal power plants reserve JWCD below $2000 \mathrm{MW}(l p w)$ has been determined by formula (1):

$$
l p w=\sum_{t=13,16,19} p w(t) \cdot l d r
$$

where $p w(t)$ is Probability of thermal reserve occurrence at the KSE system below 2000 MW during the daily demand peak on a specific day versus the hour on a working day $(t) . l d r$ is number of working days in the year. The value of 250 was taken. As it is visible in Fig. 4 interesting observations were made in 2018 only for three hours.

The calculated $l p w$ value, i.e. 8.6, was adjusted to 4 based on the data on the expected number of DSR service hours provision [4].

For the above selected hours a reversed cumulative distribution function of the energy consumption in the mine was determined (Fig. 5), which was determined based on historical data obtained for the analysed KWK. Fig. 6 presents historical data on electricity consumption in the analysed mine for 1 p.m. 


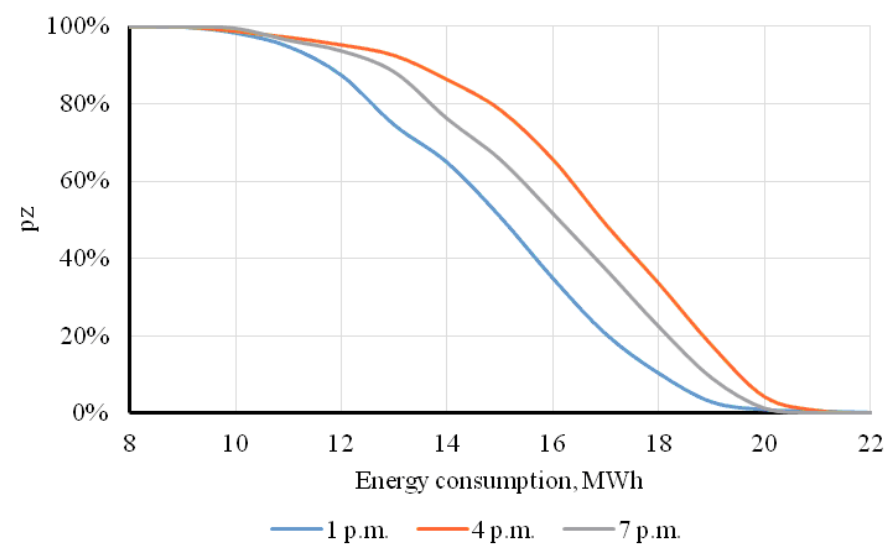

Fig. 5. Probability of higher energy consumption occurrence at the KWK than the given value for three selected hours during a working day (pz). Source: own study.

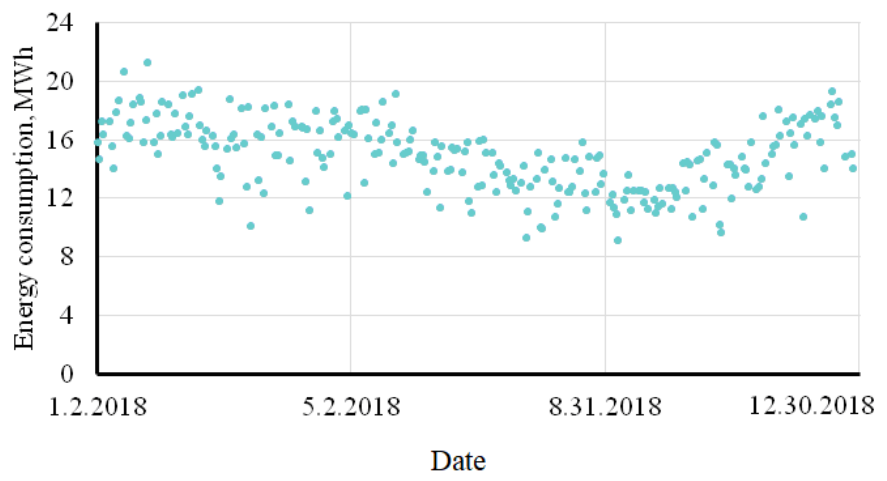

Fig. 6. Energy consumption in the analysed mine for 1 p.m. on working days. Source: Own study.

For 1 p.m. there is an almost $100 \%$ probability, that the energy consumption in the mine will be on a level of at least $10 \mathrm{MWh}$ and nearly $50 \%$ that the energy consumption will exceed $15 \mathrm{MWh}$. An assumption was made that this probability value is random and does not depend on other factor, such as external conditions or production plans.

\section{Economic analysis}

The evaluation of economic effects of the DSR service provision by the hard coal mine was calculated based on the data prepared in the previous section and on the adopted methodology of research and assumptions.

Two options of the entity participation in the DSR market were considered, i.e. 1) under a guaranteed programme, 2) under a current programme. With respect to the guaranteed programme an active participation in the DSR market is related to potential benefits as well as to fines resulting from the call non-performance. To take this fact into account in the analysis, a factor presenting a ratio of benefits (remuneration for power reduction expressed in monetary units equivalent to the price for the service) to fines (monetary charge for nonperformance of the call to reduce power) was adopted in calculations.

The following assumptions of the economic analysis within the option of active entity's participation in the guaranteed DSR programme were made to carry out calculations: 
- The considered ratio of the service price to the fine for the call non-performance: from 2 to 0.1 . The value of 2 means that the remuneration for the service performance is twice higher than the fine for non-performance, if any. In turn, the value of 0.1 means that the likely fine is ten times higher than the potential remuneration for the operator's call performance.

- The declared power reduction can range from $1 \mathrm{MW}$ to $10 \mathrm{MW}$. It was considered that the mine can be also a member of a larger group of entities on the DSR market.

- The basic service price is 3213 EUR/MWh.

- The basic price for being available on the DSR market is $24 \mathrm{EUR} / \mathrm{MWh}$.

- The period of analysis was 1 year.

- The 2018 data were the basis.

- The change of time value of money was neglected.

The analysis does not take into account specific costs of the entity operation, such as: opportunity cost, fixed costs (including staff/workers payroll), cost of production stopping and restarting. Such costs cause the an enterprise, willing to participate in the market, must achieve substantially potential revenues due to the power reduction, because the risk of incurring a loss can be significant.

Results of economic analysis, based on the risk analysis, are presented on a map Fig. 7. Calculations were carried out in accordance with the formula:

$$
P F_{g}(M, S)=o w \cdot M \cdot\left(\operatorname{pr}(M)-\frac{1}{S} \cdot p n(M)\right) \cdot \frac{l d r}{\left(\frac{\operatorname{lpw}}{4}\right)}+\lg o \cdot o g \cdot M,
$$

where $\mathrm{PFg}$ is financial revenue on service provision under the guaranteed programme depending on $\mathrm{M}$ and $\mathrm{S}$, EUR/year; $\mathrm{M}$ is the power declared to reduce, $\mathrm{MW}$; $o w$ is performance remuneration. Maximum EUR 3213 was adopted [4]; $S$ is ratio of financial benefits resulting from the service provision to a potential fine; lgo is number of hours in the year, when the enterprise is to be ready to reduce the power: 1500. Package No. 1 (summer season) working days, hours: $10.00-18.00$. Package 2 (winter season) working days, hours: $16.00-20.00$ [4]; og is readiness fee. Value of EUR 24/MWh was adopted [4]; $l d r$ is number of working days; $l p w$ is according to formula (1).

Probability of service provision on a given day $(p r)$ :

$$
p r(M)=\sum_{t=13,16,19} p w(t) \cdot p z(t, M),
$$

where $p w(t)$ is probability of thermal reserve occurrence in the KSE system below $2000 \mathrm{MW}$ during the daily demand peak on a specific day versus the hour on a working day $(\mathrm{t}) ; p z(t, M)$ is probability of higher energy consumption occurrence at the KWK than the given value calculated above the minimum $8 \mathrm{MW}(\mathrm{M})$ for selected hours during a working day $(\mathrm{t})$.

Probability of service non-provision on a given day $(p n)$ :

$$
p n(M)=\sum_{t=13,16,19} p w(t) \cdot(1-p z(t, M)) .
$$

When the mine declares reduction of power by $5 \mathrm{MW}$ and the ratio of price to fine is 0.1 , then the expected value is approx. $110000 \mathrm{EUR} / \mathrm{year}$, and when the price to fine is 2 then the expected value will be $210000 \mathrm{EUR} / \mathrm{year}$. The achieved values will depend to a large extent on the readiness fee.

The optimum reduction values are from 2 to $5 \mathrm{MW}$, but the smaller the reduction value the higher will be the costs of service actions related to the DSR market operation as well as the opportunity cost - not analysed in this paper. 


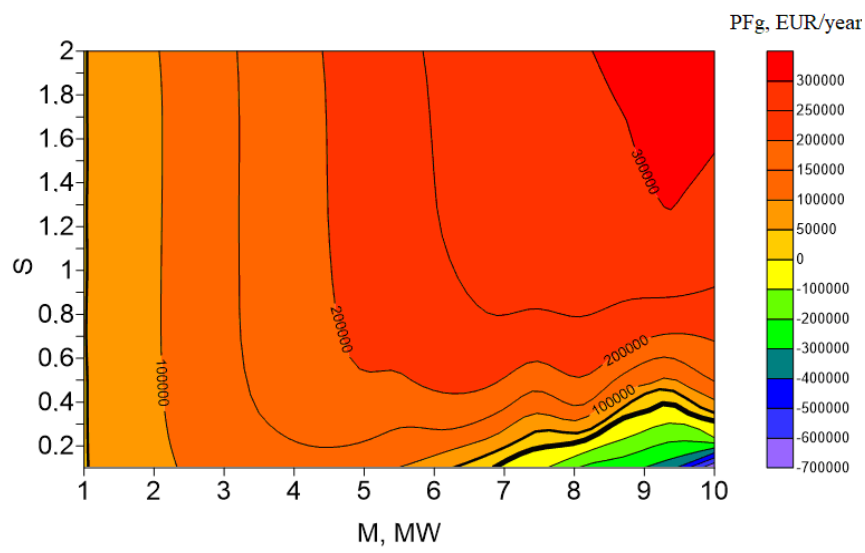

Fig. 7. Potential financial revenue (PFg, EUR/year) depending on the declared value of power reduction and the ratio of price/fine for power reduction. The light green line marks the maximum values. Own study.

In the case of the second option, taking into account the entity participation in the DSR market under the current programme, results of economic analysis were prepared using the following assumptions:

- The declared power reduction can range from $1 \mathrm{MW}$ to $10 \mathrm{MW}$.

- The basic service price is 3213 EUR/MWh in the hour.

- The period of analysis was 1 year.

- The 2018 data were the basis.

- The change of time value of money was neglected.

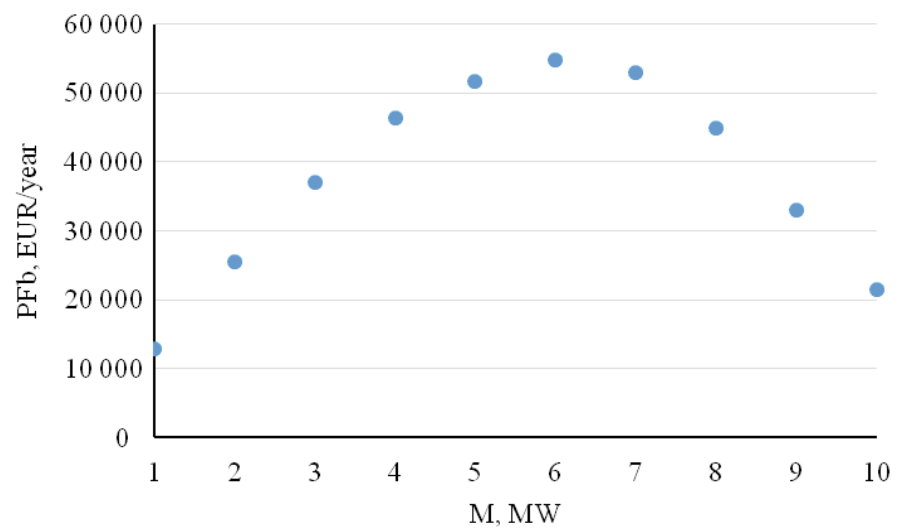

Fig. 8. Potential financial result (EUR/year) versus the declared value of power reduction for the enterprise operating on the DSR market under the current programme. Own study.

Results of calculations are presented in Fig. 8. Calculations were carried out in accordance with the formula:

$$
\operatorname{PFb}(M)=o w \cdot M \cdot \operatorname{pr}(M) \cdot \frac{l d r}{\left(\frac{l p w}{4}\right)},
$$

where $P F b$ is financial revenue on service provision under the current programme depending on M, EUR/year. 
The achieved results depend linearly on the remuneration for power reduction $\mathrm{M}$. In the current programme the highest predicted financial revenue is for the power of $6 \mathrm{MW}$.

\section{Conclusions}

The analysed mine, based on the 2018 conditions, can achieve the predicted revenue on the DSR service ranging from 1000000 to 300000 EUR/year due to participation in the guaranteed programmes and slightly more than $50000 \mathrm{EUR} /$ year in the current programme, assuming the maximum price for the service provision. These values do not consider specific costs of the mine operation, which can be related to stopping certain elements of the mine equipment and usually downtimes of their operators. The shown scale of revenue versus the total mine revenue in the best case is less than $1 / 1000$.

Despite the ordered power of $20 \mathrm{MW}$ it has been found that practically there are no possibilities to reduce the power by $10 \mathrm{MW}$, i.e. to participate independently in the DSR market. From the financial risk assessment point of view the mine can declare reduction from 1 to $10 \mathrm{MW}$ under the guaranteed programme at relatively low fines for nonperformance, at fines 10-times higher than the remuneration the declaration of the power reduction should range from 2.5 to $5.5 \mathrm{MW}$. The optimum of the declaration for the current programme is $6 \mathrm{MW}$.

There are good prospect for the DSR market development, therefore a larger number of calls should be expected in the future.

This research was supported by Mineral and Energy Economy Research Institute of the Polish Academy of Sciences.

\section{References}

1 Torriti, J., Hassan, M.G., \& Leach, M. (2010) Demand response experience in Europe: Policies, programmes and implementation. Energy, 35(4), 2010. https://doi.org/10.1016/j.energy.2009.05.021

2 Nieuwenhout, F., Cobben, J., Combrink, F., Duarte, J., \& Heskes, P. (2006). Flexible electricity grids Report of Work Package 1 EOS-LT project FLEXIBEL ECN.

3 Demand Response as a resource for the adequacy and operational reliability of the power systems. (2017).

https://www.entsoe.eu/fileadmin/user_upload/_library/publications/etso/security_of supply/Dema nd\%20Side $\% 20$ Response $\% 20$ Explanatory $\% 20$ Note.pdf

4 PSE. DSR services. (2019). [online]. Available at: http://dsr.pse.pl

5 Demand Side Response in the National Electricity Market. Case Studies. (2017). [online]. Available at: $\underline{\text { http://www.euaa.com/ }}$

6 Marwan, M., \& Kamel, F. (2011). Demand Side Response to Mitigate Electrical Peak Demand in Eastern and Southern Australia. Energy Procedia, (12), 133-142. https://doi.org/10.1016/j.egypro.2011.10.019

7 Benefits of Demand Response in Electricity Markets and Recommendations for Achieving Them (2006). U.S. Departament of Energy.

8 Rasolomampionona, D., Robak, S., Chmurski, P., \& Tomasik, G. (2010). A review of demand side response mechanisms used in different worldwide energy markets. Rynek Energii, (2), 138144.

9 Jabłońska, M. (2011) Actual trends in demand response researches. Rynek Energii, (3), 81-86. 